\title{
A EXPANSÃO dA EDUCAÇÃo SUPERIOR NO BRASIL PÓS LDB/96: ORGANIZAÇÃO INSTITUCIONAL E ACADÊMICA*
}

\author{
Marilia Costa Morosini, \\ da Pontifícia Universidade Católica do Rio Grande do Sul \\ Maria Estela dal Pai Franco, \\ da Universidade Federal do Rio Grande do Sul \\ Stella Cecilia Duarte Segenreich, \\ da Universidade Católica de Petrópolis
}

\begin{abstract}
REsumo: a expansão da Educação Superior é um fenômeno mundial. Pouquíssimas são as nações que já alcançaram o patamar universal nas taxas de Educação Superior. Via de regra, as nações desenvolvidas situam-se no patamar da educação de massa e as nações emergentes ou subdesenvolvidas ainda estão no patamar da educação elitista. $O$ presente artigo deriva de estudos da Rede Universitas e se detém na análise da expansão da Educação Superior no Brasil, especialmente no exame da organização institucional e acadêmica. O período analisado é o pós-LDB/96, quando ocorre significativo aumento no número de instituições, cursos, alunos e docentes. $O$ trabalho é de natureza qualitativa e quantitativa (dados censitários). Como resultado é apontada a complexificação do sistema, que adota distintos formatos de organização institucional e acadêmica, em consonância com as políticas de regulação, com as tendências de internacionalização, diversidade, diversificação, flexibilização e privatização.
\end{abstract}

Palavras-chave: Educação Superior. Expansão da Educação Superior. Organização Institucional. Organização Acadêmica. Rede Universitas.

\footnotetext{
* Artigo recebido em 22/08/2010 e aprovado em 26/09/2010.
} 
INTRODUÇÃO

O presente artigo tem como objetivo maior analisar as políticas públicas de expansão da Educação Superior no Brasil pós-LDB/96, em especial a organização institucional e acadêmica. Na busca ao atendimento do objeto de análise, coloca-se a seguinte questão: como a expansão da Educação Superior brasileira pós-LDB/96 se configura na organização institucional e acadêmica, sob a perspectiva de políticas públicas educacionais e sob os eixos de novas arquiteturas da EAD, de cursos tecnológicos, da internacionalização da Educação Superior e da diversidade e diversificação de modelos?

Por organização institucional, entendem-se os tipos de instituições de Educação Superior mantidos ou criados pelos documentos normativos ordenativos brasileiros pós-LDB/1996, incluídos universidades, centros universitários, faculdades isoladas, institutos superiores de educação, faculdades tecnológicas e universidades tecnológicas, que servem de referência para os censos de Educação Superior brasileira na última década. Já a organização acadêmica refere-se ao modo de oferta da Educação Superior brasileira quanto à presencialidade e às novas possibilidades de oferecimento de perfis formativos, como a dos cursos sequenciais e a dos cursos tecnológicos. A organização institucional e a modalidade acadêmica, juntamente com a organização administrativa, expressas pela natureza jurídica de IES públicas e privadas, estas últimas com as variantes de particulares, confessionais, filantrópicas e comunitárias, compõem a arquitetura acadêmica da Educação Superior brasileira.

$\mathrm{Na}$ análise da questão, os seguintes pontos são considerados: 1) o significativo movimento expansionista, no contexto pós- LDB/1996, que se caracterizou por um aumento no número de instituições, cursos, alunos, demandas e docentes, o que sinaliza para uma possível complexificação do sistema como um todo; 2) a expansão pós-LDB/1996, que parece ter atingido a base organizativa da Educação Superior, na medida em que, sob o princípio da diversidade, adota distintos formatos de organização institucional e acadêmica, os quais se configuram sob diferentes modalidades terminais (diplomas e certificados) e de modo de oferecimento (presenciais, a distância, semi-presenciais); 3) a diversidade e diversificação de formatos e de modalidades na organização institucional e acadêmica, que parecem estar em consonância com as políticas de regulação que impregnam a Educação Superior brasileira, com as tendências de internacionalização, diversidade, flexibilização e privatização; 4) a expansão da Educação Superior que se manifesta em novas formas e modalidades institucionais acadêmicas como a EAD e a educação tecnológica, derivadas da internacionalização. 
É importante ter presente que as relações complexas que modulam as políticas de expansão têm subjacente a economia liberal do mundo hodierno, a qual termina por criar relações de trabalho e de formação excludentes no seio das quais a expansão e a contenção se desenvolvem.

\section{TRAÇOS DA EXPANSÃO DA EDUCAÇÃO SUPERIOR}

Estudos sobre os cenários futuros da Educação Superior vêm sendo realizados. O de Lancrin (2007) identifica cinco fatores que merecem atenção, a saber: crescimento demográfico, participação na educação, internacionalização, economia do conhecimento e governança.

Detendo-se nos dois primeiros fatores, tal como constam da Tabela 1, constata-se que: quanto ao tamanho relativo (\%) da população segundo faixa etária escolar, em 2000, a coluna do meio, referente ao ensino médio (15-19 anos), é a que apresenta menores percentuais em relação às outras duas, ou seja, em relação à população com idade para o Ensino Fundamental (5-14 anos) e para o Ensino Superior (20-29 anos); embora o grau da frequência seja diferenciado entre países desenvolvidos e emergentes, o bloco da OECD é o que apresenta percentual similar de população em idade do Ensino Fundamental e em idade do ensino superior; o bloco dos países emergentes e subdesenvolvidos tende a apresentar maiores percentuais na faixa etária para o Ensino Fundamental. Tais dados refletem uma taxa de natalidade maior e taxa de educação menor para os subdesenvolvidos.

A análise do segundo bloco de informações - as projeções para 2015 nos países da OECD desenvolvidos - mostra que, em todas as faixas de idade escolar, há uma diminuição de percentuais, o que indica, além de uma menor taxa de natalidade, uma menor necessidade de criação de novas vagas no ensino. Lancrin (2007) afirma que, em 2030, o percentual da população em idade de cursar universidade (19-25 anos) continuará crescendo e prevê a manutenção dessa situação, pois isso vem ocorrendo também no grupo de cinco anos, que deverá entrar na universidade. Alerta para outras formas de demandas compensatórias do crescimento demográfico, como os aposentados, pessoas com mais idade, estudantes em transição, de países subdesenvolvidos, entre outros.

Já nos países emergentes e subdesenvolvidos a realidade é oposta. Para 2015, há aumento populacional nas faixas educacionais do Ensino Médio e do ensino superior. A população em idade escolar para o nível fundamental apresenta decréscimo, o que aponta para a uma diminuição da taxa de natalidade. Para os outros dois níveis, identifica-se a continuidade da expansão educacional e consequente necessidade de novas vagas. No caso do Brasil, 
considerando o ano de 2000 como 100, o índice é de 104 para o nível superior e de 91 para o nível médio.

Tabela 1 - Tamanho relativo e mudanças esperadas na idade escolar da populações (2000), \% população segundo idade escolar sobre total da população e projeções da população segundo idade escolar

\begin{tabular}{|c|c|c|c|c|c|c|c|c|c|}
\hline \multicolumn{10}{|c|}{ Índice de mudança na população em idade escolar - ano base $2000(=100)$} \\
\hline \multirow[b]{2}{*}{ Países da OECD } & \multicolumn{3}{|c|}{$\begin{array}{c}\text { \% população } \\
\text { segundo idades }\end{array}$} & \multicolumn{2}{|c|}{ 5-14 anos } & \multicolumn{2}{|c|}{ 15-19 anos } & \multicolumn{2}{|c|}{ 20-29 anos } \\
\hline & $\begin{array}{l}5-14 \\
\text { anos }\end{array}$ & \begin{tabular}{|l|}
$15-19$ \\
anos
\end{tabular} & $\begin{array}{c}20-29 \\
\text { anos }\end{array}$ & 1990 & 2015 & 1990 & 2015 & 1990 & 2015 \\
\hline Austrália & 14 & 7 & 15 & 92 & 99 & 102 & 102 & 97 & 106 \\
\hline Áustria & & 6 & 13 & 96 & 68 & 108 & 86 & 131 & 93 \\
\hline Bélgica & 12 & 6 & 13 & 99 & 79 & 108 & 92 & 118 & 96 \\
\hline Canadá & 13 & 7 & 14 & 93 & 89 & 94 & 96 & 113 & 109 \\
\hline Republica Tcheca & 12 & 7 & 17 & 126 & 71 & 121 & 66 & 80 & 73 \\
\hline Dinamarca & 12 & 5 & 14 & 91 & 88 & 134 & 122 & 113 & 93 \\
\hline Finlândia & 12 & 6 & 12 & 101 & 76 & 91 & 88 & 115 & 103 \\
\hline França & 13 & 7 & 14 & 103 & 97 & 108 & 94 & 107 & 93 \\
\hline Alemanha & 11 & 6 & 12 & 94 & 75 & 97 & 89 & 140 & 101 \\
\hline Grécia & 10 & 7 & 15 & 128 & 84 & 110 & 74 & 95 & 71 \\
\hline Hungria & 12 & 7 & 16 & 124 & 70 & 123 & 76 & 81 & 74 \\
\hline Islândia & 16 & 8 & 15 & 95 & 86 & 100 & 99 & 102 & 105 \\
\hline Irlanda & 15 & 9 & 16 & 122 & 114 & 98 & 80 & 79 & 89 \\
\hline Itália & 10 & 5 & 14 & 112 & 84 & 141 & 87 & 114 & 70 \\
\hline Japão & 10 & 6 & 15 & 129 & 92 & 133 & 82 & 91 & 69 \\
\hline Coréia & 14 & 8 & 17 & 118 & 89 & 117 & 81 & 103 & 79 \\
\hline Luxemburgo & 12 & 5 & 13 & 80 & 109 & 88 & 124 & 107 & 130 \\
\hline México & 23 & 11 & 19 & 98 & 97 & 100 & 105 & 77 & 103 \\
\hline Holanda & 12 & 6 & 13 & 91 & 85 & 118 & 106 & 124 & 99 \\
\hline Nova Zelândia & 15 & 7 & 14 & 87 & 91 & 107 & 109 & 108 & 113 \\
\hline Noruega & 13 & 6 & 14 & 88 & 85 & 120 & 113 & 111 & 103 \\
\hline Polônia & 14 & 9 & 15 & 123 & 68 & 85 & 59 & 86 & 89 \\
\hline Portugal & 11 & 7 & 16 & 129 & 96 & 128 & 86 & 92 & 69 \\
\hline Eslováquia & $\mathrm{m}$ & $\mathrm{m}$ & $\mathrm{m}$ & 120 & 71 & 96 & 65 & 85 & 85 \\
\hline Espanha & 10 & 7 & 16 & 138 & 84 & 131 & 71 & 98 & 62 \\
\hline Suécia & 13 & 6 & 13 & 84 & 61 & 112 & 89 & 111 & 108 \\
\hline Suíça & 12 & 6 & 12 & 91 & 70 & 107 & 94 & 139 & 102 \\
\hline Turquia & 20 & 10 & 19 & 106 & 99 & 91 & 103 & 77 & 99 \\
\hline Reino Unido & 13 & 6 & 13 & 93 & 80 & 104 & 98 & 119 & 105 \\
\hline
\end{tabular}




\begin{tabular}{|l|c|c|c|r|r|r|r|r|r|}
\hline \multicolumn{1}{|c|}{ Índice de mudança na população em idade escolar - ano base 2000 (=100) } \\
\hline & \multicolumn{2}{|c|}{$\begin{array}{c}\text { \% população } \\
\text { segundo idades }\end{array}$} & \multicolumn{5}{c|}{$5-14$ anos } & \multicolumn{1}{|c|}{$15-19$ anos } & \multicolumn{2}{c|}{$20-29$ anos } \\
\hline Países da OECD & $\begin{array}{c}5-14 \\
\text { anos }\end{array}$ & $\begin{array}{c}15-19 \\
\text { anos }\end{array}$ & $\begin{array}{c}20-29 \\
\text { anos }\end{array}$ & 1990 & 2015 & 1990 & 2015 & 1990 & 2015 \\
\hline Estados Unidos & 14 & 7 & 13 & 87 & 96 & 89 & 109 & 111 & 120 \\
\hline Média OECD & 13 & 7 & 15 & 105 & 85 & 109 & 91 & 104 & 94 \\
\hline
\end{tabular}

\section{Outros participantes}

\begin{tabular}{|l|r|r|r|r|r|r|r|r|r|}
\hline Argentina & 18 & 9 & 16 & 98 & 106 & 85 & 106 & 78 & 110 \\
\hline Brasil & 22 & 11 & 18 & 104 & 98 & 86 & 91 & 88 & 104 \\
\hline Chile & 19 & 8 & 16 & 87 & 97 & 96 & 112 & 103 & 118 \\
\hline China & 18 & 7 & 16 & 91 & 82 & 122 & 95 & 107 & 99 \\
\hline Egito & 23 & 12 & 17 & 88 & 96 & 71 & 105 & 82 & 138 \\
\hline Índia & 25 & 9 & 17 & 88 & 101 & 85 & 112 & 85 & 125 \\
\hline Indonésia & 20 & 11 & 19 & 99 & 94 & 91 & 98 & 83 & 107 \\
\hline Jamaica & 20 & 10 & 18 & 101 & 92 & 93 & 93 & 94 & 111 \\
\hline Jordânia & 27 & 12 & 20 & 78 & 143 & 72 & 139 & 57 & 124 \\
\hline Malásia & 22 & 10 & 18 & 86 & 102 & 79 & 116 & 87 & 132 \\
\hline Paraguai & 26 & 11 & 16 & 78 & 122 & 71 & 127 & 81 & 154 \\
\hline Peru & 23 & 10 & 18 & 95 & 100 & 87 & 105 & 81 & 117 \\
\hline Filipinas & 24 & 11 & 18 & 85 & 105 & 82 & 118 & 80 & 132 \\
\hline Federação Russa & 13 & 8 & 15 & 114 & 62 & 86 & 53 & 101 & 93 \\
\hline Tailândia & 16 & 9 & 19 & 108 & 99 & 102 & 99 & 94 & 92 \\
\hline Tunísia & 22 & 11 & 18 & 102 & 92 & 83 & 79 & 83 & 108 \\
\hline Uruguai & 16 & 8 & 16 & 99 & 102 & 102 & 109 & 87 & 102 \\
\hline Zimbábue & 25 & 12 & 20 & 78 & 116 & 74 & 129 & 79 & 156 \\
\hline $\begin{array}{l}\text { Média Outros } \\
\text { participantes }\end{array}$ & 21 & 10 & 17 & 93 & 100 & 87 & 105 & 86 & 118 \\
\hline
\end{tabular}

Fontes: OECD/UIS WEI and UM Population Division, apud Lancrin, 2007,p.5-6

A Secretaria Executiva da Conferência Mundial de Educação Superior da UNESCO, em 2009, (UVALIĆ-TRUMBIĆ, 2010) declara que, na sociedade do conhecimento, os diplomas são considerados passaportes para um bom futuro, o que vem causando uma tendência à massificação do ensino superior. Globalmente, as taxas de participação na Educação Superior têm crescido de 19\% em 2000 para 26\%, em 2007. Foram 150,.6 milhões de alunos matriculados no ensino superior em 2007, o que representa um aumento de $53 \%$ em face de 2000. Nos países de renda baixa, as taxas de participação segundo a idade foram menores e aumentaram de 5\% em 2000, para 7\% em 2007.

Na América Latina, desde meados do século passado, é marcante a expansão, tanto que, de 1950 a 2003, o número de IES passou de 75 para 
1.859. No mesmo período, as matriculas estudantis passaram de 267.000 para 12 milhões (http://www.iesalc.unesco.org.ve/pruebaobservatorio/boletin118. htm. Acesso: 20 abr. 2006).

É inegável que no Brasil, no contexto pós-LDB/96, houve significativo movimento expansionista. A análise dos censos da Educação Superior do INEP permite afirmar que o crescimento não só ocorreu no âmbito do sistema mas que o movimento expansionista exige um olhar mais apurado, para entender a relação sistema-segmentos, tendo em conta a perda de espaço das universidades, o crescimento das instituições privadas, além de outros pontos indicativos de desequilíbrios, tensões, distorções. No estudo dos censos de 1991 a 2004, a Rede Universitas amplia suas análises para os 27 Estados Brasileiros e encontra nove pontos basilares para entender o sistema de Educação Superior brasileiro: 1) o crescimento do sistema; 2) o crescimento do sistema pela via das IE privadas; 3) a perda de espaço das universidades quando comparadas com outras organizações acadêmicas de ES; 4) a centralização progressiva do SES; 5) a concentração geográfica do SES; 6) a inserção social através da incorporação de outras formas desenvolvidas pelo setor privado; 7) o desequilíbrio de ofertas de formação profissional; 8) a ociosidade de vagas; 9) a qualificação das funções docentes (Ristoff \& Giolo, 2006).

O Censo da Educação Superior de 2008, registrou a existência, no Brasil, de 2.252 instituições de Educação Superior (IES) que, no período da coleta de dados, tinham, pelo menos, um curso em funcionamento. Isso implica crescimento de 144,3\% em 12 anos. Segundo Segenreich e Castanheira (2009), na análise do crescimento das IES por categoria administrativa - público x privado -, já é possível perceber os caminhos trilhados pela expansão do ensino superior, tomando-se como marcos a LDB/96 e o PNE/2001. A Tabela 2 permite ratificar algumas evidências já constatadas no estudo promovido pelo INEP por Ristoff e Giolo (apud SeGENREICH, CASTANHeIRA, 2009).

Tabela 2 - Número de IES por esfera administrativa (pública e privada) - Brasil, 1996 a 2008.

\begin{tabular}{|c|r|r|r|c|c|}
\hline \multirow{2}{*}{ Ano } & \multirow{2}{*}{ Brasil } & \multicolumn{2}{|c|}{ Pública } & \multicolumn{2}{c|}{ Privada } \\
\cline { 3 - 6 } & & Total & $\%$ & Total & $\%$ \\
\hline 1996 & 922 & 211 & 27,9 & 711 & 77,1 \\
\hline 2001 & 1.391 & 183 & 13,2 & 1.208 & 86,8 \\
\hline 2008 & 2.252 & 236 & 10,4 & 2016 & 89,6 \\
\hline $1996 / 2001 \Delta \%$ & 50,9 & $-14,3$ & --- & 69,9 & --- \\
\hline $2001 / 2008 \Delta \%$ & 61,9 & 29,0 & --- & 66,9 & --- \\
\hline $1996 / 2008 \Delta \%$ & 144,3 & 11,8 & --- & 183,5 & --- \\
\hline
\end{tabular}


Fica evidente o período crítico de retração do setor público (-14,3 de percentual de crescimento entre 1996 e 2001), em contraste com a expansão de 69,9 por cento de IES da iniciativa privada no mesmo período. Há uma retomada do crescimento do setor público pós-PNE (29\% entre 2001 e 2008), que, no entanto, não se iguala ao crescimento do setor privado em igual período $(66,9 \%)$, apesar de este apresentar um pequeno declínio em relação ao período anterior (69,9\%). A realidade do sistema mostra, nos dados do Censo de 2008, que as instituições de Educação Superior da rede privada representam $89,6 \%$ do sistema como um todo.

O crescimento do setor público - federal, estadual e municipal - no segundo período se deve, em boa parte, à criação dos Centros de Educação Tecnológica, em relação estreita, pois, com a categoria diferenciação que será abordada em sequência. Entretanto, existem outros processos de diferenciação, em termos de esfera administrativa que não podem deixar de ser analisados. Um deles, por exemplo, trata da diferenciação de IES da rede privada em dois subgrupos de esfera administrativa, que até 1996 constituíam uma única categoria, estabelecida nas estatísticas do INEP a partir de 1997: a) instituições privadas particulares, que se apresentam como organizações com fins lucrativos; e b) instituições privadas confessionais, comunitárias e filantrópicas, que se declaram sem fins lucrativos. Registramos, nesse momento, o fato de que, no ano em que essa diferenciação foi estabelecida, existiam 689 instituições privadas, das quais 382 particulares (55.4\%) e 307 comunitárias, confessionais ou filantrópicas $(44,6 \%)$, proporção bastante equilibrada. Já no Censo de 2008, foram registradas 2.016 IES privadas, das quais 78,6 são particulares.

No que toca à forma de organização acadêmica, a única que permaneceu inalterada no período 1996-2008 foi universidade.

Analisando-se o índice de crescimento de cada tipo de IES, podese perceber que somente as faculdades integradas apresentam acentuado índice negativo de crescimento $(31,8 \%)$ no período 1996-2001, enquanto as faculdades isoladas crescem $61,1 \%$. O movimento de migração das IES de uma para outra categoria de organização acadêmica é representado, em parte, pelo processo de evolução de algumas dessas faculdades integradas até se transformarem em universidades e, em parte, por sua migração para uma nova forma de IES, o Centro Universitário, presente nas estatísticas do MEC desde 1997.

Outras mudanças na tipologia das IES por organização acadêmica, dessa vez determinadas pelo MEC, também podem ser registradas. As faculdades integradas, por exemplo, foram incorporadas às faculdades, escolas 
e institutos com o título geral de Faculdades, a partir de 2008. Dessa forma, os índices de crescimento tiveram que ser calculados segundo essa nova lógica. Quanto às instituições especificamente responsáveis pela educação tecnológica, verificou-se um acréscimo no período 2001-2006, por ocasião do estudo do INEP, mas os dados do Censo da Educação Superior de 2008 registram o mesmo total de instituições de 2001 (34 IES), na medida em que foram excluídos os cursos e instituições da rede privada. Constatou-se mais um processo significativo de diferenciação institucional e de modalidades de ensino, desta vez na área da educação tecnológica.

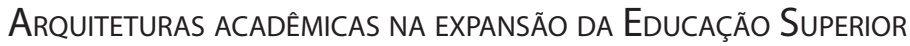

A LDB/1996, dentre outras medidas, flexibilizou as formas organizacionais de oferta de Educação Superior, privilegiando a diversidade de formatos institucionais e modalidades acadêmicas e sua diversificação, repercutindo na questão da privatização do ensino. Merecem destaque as seguintes medidas, que serão tratadas em partes separadas neste artigo: EAD e Educação Tecnológica, internacionalização da Educação Superior e modelos acadêmicos.

\section{EAD E EDUCAÇÃo TECNOLÓGICA}

A educação a distância e a educação tecnológica, como formas organizativas e modalidades de oferta de cursos, têm ocupado, nos últimos anos, maior espaço nas políticas públicas de expansão. A Educação a distância surgiu como integrante do sistema de educação formal desde que foi incluída como uma das propostas alternativas de diversificação do sistema de ensino na LDB. Sabe-se, entretanto, que, mesmo antes da lei, várias iniciativas governamentais já vinham anunciando essa medida, como a criação, em 1994, do Sistema Nacional de Educação a Distância pelo Decreto 1.237/1994 e, em dezembro de 1995, a criação da Secretaria de Educação a Distância no MEC.

Paralelamente, várias universidades começaram a desenvolver projetos em educação a distância criando, em alguns casos, coordenações e laboratórios de EAD em sua estrutura. Tais iniciativas demandaram o estabelecimento de políticas públicas que, traduzidas em decretos, portarias e resoluções, procuravam definir melhor o campo de atuação da EAD nos diferentes níveis de ensino. Um dos primeiros marcos regulatórios do MEC foi estabelecer a exigência de um credenciamento institucional específico para que as instituições de ensino superior pudessem oferecer cursos a distância (SEGENREICH, 2006). Esses cursos podem ser sequenciais, de graduação e de 
pós-graduação stricto e lato sensu. As IES credenciadas e autorizadas para oferecer cursos superiores de graduação a distância estão automaticamente autorizadas a oferecer cursos de pós-graduação lato sensu. Quanto aos cursos de pós-graduação stricto sensu, sua oferta depende, ainda, de regulamentação específica da CAPES.

É importante registrar o crescimento das IES credenciadas para EAD, cuja expansão nas redes pública e privada, é mostrada na Tabela 3.

Tabela 3: Evolução do número de instituições credenciadas para EAD nas esferas pública e privada

\begin{tabular}{|c|c|c|c|c|c|}
\hline Anos & Totais & Público & $\%$ & Privado & $\%$ \\
\hline 2001 & 10 & 10 & 100 & - & - \\
\hline 2002 & 25 & 16 & 64 & 09 & 36 \\
\hline 2003 & 37 & 22 & 59 & 15 & 41 \\
\hline 2004 & 45 & 23 & 51 & 22 & 49 \\
\hline 2005 & 61 & 23 & 38 & 38 & 62 \\
\hline 2006 & 77 & 31 & 40 & 46 & 60 \\
\hline 2007 & 97 & 45 & 46 & 52 & 54 \\
\hline 2008 & 115 & 59 & 51 & 56 & 49 \\
\hline
\end{tabular}

Fonte: MEC/Inep/Deaes

Verifica-se, nos primeiros anos de implantação dessa modalidade de ensino, a presença significativa das instituições públicas, por conta dos consórcios estabelecidos para certificação de professores:Veredas, em Minas Gerais, CEDERJ, no Rio de Janeiro e PEC, em São Paulo. No período 2005-2007, essa situação se inverte, com presença majoritária das instituições privadas. Em 2008, as instituições públicas voltam a preponderar, em função da presença crescente das instituições tecnológicas e da implantação da Universidade Aberta do Brasil.

\section{UnIVERSIDADE ABERTA Do BRASIL (UAB)}

A UAB foi instituída oficialmente pelo Ministério de Educação em 2006, para unificar ações, programas, projetos, atividades em direção à expansão no oferecimento de ensino superior gratuito e de qualidade. Foi criada para as IES públicas a fim de capacitar, principalmente, professores para a Educação Básica. A rede UAB já possuía, em janeiro de 2009, 290 polos aprovados, dos quais 52 , na região norte (SEGENREICH, 2009). É um programa que congrega secretarias do MEC e de órgãos auxiliares, como a CAPES, e prevê a integração entre instituições públicas de ensino superior, com estados e municípios como parceiros. O que propõe é um "sistema de Universidade Aberta 
pela articulação entre as universidades já existentes, possibilitando o acesso ao ensino público superior em municípios que não possuem ensino público superior ou naqueles que possuem, mas não em quantidade suficiente para todos os cidadãos." (http://portal.mec.gov.br) A Universidade funciona por meio de polos de apoio presencial para acompanhamento, nos municípios e estados, em torno de cinco eixos: 1) expansão pública do Sistema de Educação Superior (SES) - democratização e acesso; 2) aperfeiçoamento dos processos de gestão das IES - expansão consoante com as propostas dos estados e municípios; 3) avaliação da Educação Superior a distância - processos de flexibilização e regulação; 4) contribuições para a investigação em Educação Superior a distância no país; 5) financiamento dos processos em Educação Superior a distância (http:// www.uab.capes.gov.br).

Tabela 4 - Evolução do número de instituições credenciadas para EAD, cursos e vagas oferecidas

\begin{tabular}{|c|r|r|r|}
\hline Anos & IES & Cursos & Vagas \\
\hline 2001 & 10 & 16 & 6.856 \\
\hline 2002 & 25 & 46 & 24.389 \\
\hline 2003 & 37 & 52 & 23.025 \\
\hline 2004 & 45 & 107 & 113.079 \\
\hline 2005 & 61 & 189 & 423.411 \\
\hline 2006 & 77 & 349 & 813.550 \\
\hline 2007 & 97 & 408 & 1.541 .070 \\
\hline 2008 & 115 & 647 & 1.699 .489 \\
\hline $2001-2008 \Delta \%$ & 1.050 & 3.943 & 24.688 \\
\hline
\end{tabular}

Fonte: MEC/Inep/Deaes

Entretanto, se o quadro de instituições parece indicar uma forte presença da esfera pública na EAD, constata-se, conforme mostra a Tabela 4, que existe uma oferta explosiva de cursos e, principalmente, de vagas, o que pode sugerir uma presença bastante forte da esfera privada, que merece ser pesquisada.

\section{Os Centros Federais de Educação Tecnológica (CEFET)}

De acordo com o Decreto n. 5.224/2004, de criação dos CEFET, eles "são instituições especializadas na oferta de educação tecnológica, nos diferentes níveis e modalidades de ensino, com atuação prioritária na área tecnológica." (BRASIL, 2004, art. 1ㅇ․ § 10) Sua finalidade é formar e qualificar profissionais na área tecnológica para diferentes setores da economia, além de "realizar pesquisa aplicada e promover o desenvolvimento tecnológico 
de novos processos, produtos e serviços", articulando-se com ros setores produtivos e a sociedade (art. $2^{\circ}$.). São autarquias federais que podem ministra ensino superior de graduação e de pós-graduação, visando à formação de profissionais e especialistas na área tecnológica. Podem oferecer, ainda, formação pedagógica de professores e especialistas, além de cursos de nível básico, técnico e tecnológico e do ensino médio (HTTP://PORTAL.MEC.GOV.BR/SETEC).

Os cursos tecnológicos de graduação são estruturados para atender aos diversos setores da economia, ministram formação profissionalizante abrangendo áreas especializadas e conduzem ao diploma de tecnólogo, visando atender o mercado de trabalho. Segundo Segenreich e Castanheira (2009), os cursos superiores de tecnologia não são uma criação da LDB/1996, pois já existiram e foram extintos - como, por exemplo, os cursos de engenharia de operação -, ou ainda subsistem sob a rubrica de curso de formação de tecnólogos. O que é novo é sua inclusão entre os cursos de graduação com todas as prerrogativas de acesso aos níveis mais elevados da formação em nível superior. Essa política se evidencia no fato de o INEP não diferenciar, em suas estatísticas mais gerais, os bacharelados, licenciaturas ou cursos de tecnologia. Entretanto, ao se analisar a oferta de cursos pelos Centros de Educação Tecnológica (CET) e Faculdades Tecnológicas (FAT), assim como dos cursos de graduação a distância, que vêm crescendo significativamente no Brasil, iremos perceber a presença desse tipo de curso, tendo em vista que as estatísticas do MEC apresentam os dados da educação a distância por instituição e curso. No que se refere à oferta de cursos pelos CET e FAT, a Tabela 5 dá uma visão de como esses cursos se comportavam antes da mudança no registro das estatísticas, em 2008.

Tabela 5: Distribuição dos cursos oferecidos pelos CET/FAT e percentual de crescimento por categoria administrativa (pública e privada) - Brasil 1999 a 2006.

\begin{tabular}{|c|r|r|r|r|c|}
\hline \multirow{2}{*}{ Ano } & \multirow{2}{*}{ Brasil } & \multicolumn{2}{|c|}{ Pública } & \multicolumn{2}{c|}{ Privada } \\
\cline { 3 - 6 } & & Total & $\%$ & \multicolumn{1}{c|}{ Total } & $\%$ \\
\hline 1999 & 74 & 74 & 100 & - & - \\
\hline 2001 & 183 & 153 & 83,6 & 30 & 16,4 \\
\hline 2006 & 959 & 360 & 37,5 & 599 & 62,5 \\
\hline $2001 / 2006 \Delta \%$ & 424,0 & 135,3 & - & $1.896,7$ & - \\
\hline
\end{tabular}

Fonte: MEC/Inep/Deaes

Os dados da Tabela 5 ratificam as tendências de rápida privatização do setor das IES voltadas para a educação tecnológica. Em 2008, ficou mais difícil conseguir esses dados pelas razões acima apresentadas. 
Como se pode ver, são múltiplos e diversos os formatos organizativos acadêmicos e as modalidades de oferta para os que concluíram o ensino médio ou equivalente Enquanto as modalidades podem ser presenciais, semipresenciais ou a distância, os perfis formativos encontram espaço nos cursos sequenciais e nos cursos superiores de tecnologia.

\section{INTERNACIONALIZAÇÃO DA EDUCAÇÃO SUPERIOR E A EXPANSÃO}

A partir da década de 90 e com maior predomínio a partir dos anos 2000, o modelo de transnacionalização da Educação Superior vem assumindo lugar como uma das manifestações da internacionalização da Educação Superior. É um conceito que abarca processos que vão além da nação, sem respeito a barreiras nacionais e regionais, e não têm a noção de relações entre países ou instituições. É um conceito ainda muito ligado ao ensino. Referese aos cursos, partes de curso ou outros serviços educacionais oferecidos aos estudantes de países diferentes daquele em que a IES fornecedora está baseada. Nessa proposta de transnacionalização, o sul, é o lado da balança mais fraco na mercadoria negociada - o conhecimento -, e pode ser abafado por um modelo isomórfico e idealizado do norte.

Estudando os efeitos da globalização sobre a mudança organizacional da Educação Superior, estes são considerados de longo prazo e ambíguos e podem ser identificadas duas interpretações opostas - a tese da convergência (isomórfica), que enfatiza o processo de homogeneização dos efeitos, e a tese da divergência (idiossincrática), que enfatiza o processo de respostas à globalização, diferente, pluralístico e localizado. Vaira (2004) propõe uma terceira possibilidade - o alomorfismo organizacional, que integra as perspectivas anteriores e interpreta a mudança como dinâmica. Reconhece que, apesar das organizações adaptarem padrões institucionais frente a suas estruturas formais e níveis de organização, bem como ao seu contexto social, é possível identificar um conjunto de padrões institucionais comuns ou de arquétipos institucionais que estruturam a organização institucional e seus comportamentos.

Entretanto, entre o isomórfico, o idiossincrático e o alomórfico existe, hoje, a tendência da multinacionalização da educação superior, compreendida como programas acadêmicos ou IES pertencentes a um determinado país que são oferecidos em outros países. Geralmente, a multinacionalização marca relações entre desiguais e tem como objetivo maior o lucro. As IES estrangeiras dominam a instituição local ou novas instituições são baseadas em idéias estrangeiras e valores não locais. (AltBACH, 2004).

São identificados: 
1. Estabelecimento de campus no estrangeiro por iniciativa local, com fortes relações com as instituições estrangeiras e, geralmente, supervisionadas pelas mesmas e acreditadas no país matriz. O currículo é o da instituição estrangeira e a língua, o inglês. Os professores são oriundos da Escola e o currículo é o da escola com focus internacional. Refere-se a um pequeno número de universidades;

2. modelo universitário padrão de exportação. Caracteriza-se pelo oferecimento de curso no exterior por instituição de país industrializado, geralmente para países em desenvolvimento. $\mathrm{O}$ anfitrião pode ser uma corporação sem ligação alguma com a educação, uma instituição educacional ou então uma combinação das duas alternativas anteriores;

3. programas conjuntos (joint degrees) oferecidos por instituições de educação superior em dois ou mais países; e

4. Mcdonaldização da Educação Superior, que é caracterizada pela oferta de cursos por instituição, no exterior, via pacote, através de franchising. A universidade do exterior cede seu nome e seu currículo, providencia alguma supervisão e o controle de qualidade é realizado por uma instituição acadêmica ou, então, por firma de negócios.

Nesse predomínio da transnacionalização, da mcdonaldização, do capitalismo acadêmico, muitas vezes denominado de turbocapitalismo, corre-se o risco de ser consolidada a era neocolonialista na Educação Superior, uma nova era de poder e influência, na qual corporações multinacionais, conglomerados de mídia e grandes universidades procuram dominar o mercado do conhecimento, não só por razões políticas e ideológicas, mas principalmente por ganhos comerciais. Os governos não estão inteiramente fora desse quadro de negociações - eles oferecem alguma assistência às companhias que estão atuando em seus países e têm um interesse residual em manter essa influência. O resultado é sempre o mesmo: a perda da autonomia cultural e intelectual pelos menos poderosos. (ALTBACH, 2004)

Sintetizando as discussões sobre a internacionalização da Educação Superior, seu embasamento teórico aponta para: a transnacionalização universitária como decorrência do processo de globalização; o acelerado processo de formulação de políticas educacionais públicas estatais e não estatais de transnacionalização, não mais entre países do Mercosul, mas extensível à América Latina e à União Europeia; a consolidação do Estado avaliativo (NEAVE, 1988), regulador e supervisor na educação, destacando sua marca na Educação Superior, através de uma rede complexa e minuciosa de políticas educacionais públicas formuladas pelo Estado e com a legitimidade da comunidade. 
O que hoje se verifica é o acelerado processo de expansão da Educação Superior em quase todos os países, principalmente no Brasil, com a perspectiva de cobertura de matrícula para 30\% da população de 18-24 anos e a preocupante possibilidade da classificação da Educação Superior como serviço no âmbito do Acordo Geral sobre o comércio de serviços - General Agreement for Trade in Services (GATS) - direcionada pela Organização Mundial do Comércio (OMC). Acrescenta-se o predomínio do conceito isomórfico de qualidade e de privilegiamento da meritocracia. É neste contexto que a categoria internacionalização universitária merece destaque.

\section{MOdELOS ACADÊMICOS}

A diversificação de modelos institucionais no período pós-LDB/1996 vem acompanhada da diversidade nas modalidades de oferecimento. Não é de surpreender que expressem múltiplas alternativas, as quais influenciam enormemente a configuração do sistema de Educação Superior nesse início de século. Não surpreende também que a questão das novas formas tenha suscitado atenção de estudos, pois elas envolvem novas organizações institucionais, novos tipos de curso, novas modalidades de ensino que, de algum modo, repercutem no sistema de Educação Superior e em seus modelos (Seggenreich, Castanheira, 2009; Franco, 2009). As novas formas organizacionais e modalidades acadêmicas ancoradas na diversidade e na diferenciação têm presença no processo de diferenciação no sistema de Educação Superior.

Entre as novas organizações institucionais e modalidades acadêmicas não se há de esquecer os cursos sequenciais, pelo potencial de diálogo entre conhecimentos de diferentes campos e a estruturação proposta na nova universidade. A idéia de curso sequencial de formação específica surgiu no processo de regulamentação dos cursos sequenciais e veio, na realidade, atender aos interesses das IES, no sentido de oferecer cursos de curta duração, mais voltados para o mercado de trabalho e que fornecessem diplomas. Tais cursos certamente favorecem a universidade de mercado, tendência de âmbito macrossocietário.

A organização institucional-acadêmica da Universidade Nova foi uma proposta base de reestruturação curricular gerada em 2006 na Universidade Federal da Bahia (UFBA) e que dá ênfase a dois ciclos: um primeiro, de formação geral (bacharelados interdisciplinares) e o segundo dirigido para a formação acadêmica e profissional. Muitas das propostas da Universidade Nova estavam presentes na formulação inicial do REUNI que, após debates e questionamentos, foi tendo alterada sua estrutura, de modo a abrigar projetos institucionais que sinalizaram para um expressivo movimento de 
expansão das universidades públicas federais em todo o país. Resgatar a especificidade destes projetos, as concepções presentes nos mesmos, as lógicas expansionistas e as implicações institucionais é fundamental para a compreensão desse movimento no campo da Educação Superior brasileira.

É pertinente lembrar que a década de 1990 foi marcada pelo massivo crescimento da rede privada de IES, mas também por um processo de metamorfose das públicas, em decorrência de cortes orçamentários. Muitas universidades públicas passaram a focalizar mais o ensino do que a pesquisa. Esse cenário vem sofrendo alterações, sobretudo após 2004, por meio da contratação de novos docentes, servidores e aumento das verbas de custeio, no caso das Universidades Federais. No entanto, pós-LDB/1996, houve, também, uma expansão da rede pública, derivada da criação de diferentes tipos de IES e de universidades, especialmente na primeira década dos anos 2000, que se caracterizou pela expansão da rede federal de IES. Foram criadas dez universidades federais: três por desmembramento de universidades já existentes, seis, por transformação de escolas, faculdades e universidades especializadas e cinco universidades novas. Por desmembramento: Universidade Federal do Recôncavo da Bahia (UFRB), em 2005; Universidade Federal da Grande Dourados (UFGD), em 2005; Universidade Federal do Oeste do Pará (UFOPA), em 2009. Por transformação: Universidade Federal do Triângulo Mineiro (UFTM), em 2005; Universidade Federal Tecnológica do Paraná (UFTPR), em 2005; Universidade Federal Rural do Semi-Árido (UFERSA), em 2005; Universidade Federal dos Vales do Jequitinhonha e do Mucuri (UFVJM), em 2005; Universidade Federal de Alfenas (UNIFAL), em 2005, e Universidade Federal de Ciências da Saúde de Porto Alegre (UFCSPA), em 2008. Universidades Novas: Universidade Federal do Pampa (Unipampa), em 2008; Universidade Federal do ABC (UFABC), em 2005; Universidade Federal da Integração Luso-Afrobrasileira (Unilab), em 2010; Universidade Federal da Integração Latino-Americana (Unila), em 2010; Universidade Federal da Fronteira Sul (UFFS), em 2009.

Voltando à questão da diferenciação de esferas administrativas, já ilustrada com a diferenciação no interior da rede privada, a Tabela 6 descreve a distribuição de IES por organização acadêmica no período 1996-2008. Nela, procurou-se representar todos os tipos de IES que integraram ou integram o atual sistema de Educação Superior, segundo os dados dos censos do INEP. Basta um primeiro olhar para a tabela para constatar uma série de mudanças na própria matriz da organização acadêmica do sistema da Educação Superior, o que se constitui um desafio para a descrição da trajetória de algumas modalidades institucionais em um período mais longo (1996 2008). 
Tabela 6 - Distribuição percentual e taxa de crescimento do número de IES por organização acadêmica - Brasil, 1996 a 2008

\begin{tabular}{|c|c|c|c|c|c|c|}
\hline \multirow[b]{2}{*}{ Ano } & \multirow[b]{2}{*}{ Brasil } & \multicolumn{5}{|c|}{ Organização Acadêmica } \\
\hline & & Universidades & $\begin{array}{c}\text { Centros } \\
\text { Universitários }\end{array}$ & $\begin{array}{l}\text { Faculdades } \\
\text { Integradas }\end{array}$ & $\begin{array}{c}\text { Faculdades, } \\
\text { Escolas, } \\
\text { Institutos }\end{array}$ & CEFET \\
\hline 1996 & 922 & 136 & ---- & 143 & 643 & --- \\
\hline \multirow[t]{2}{*}{2001} & 1.391 & 156 & 66 & 99 & 1.036 & 34 \\
\hline & & & & & & CET/FAT \\
\hline 2006 & 2252 & 183 & 119 & 116 & 1649 & 208 \\
\hline \multicolumn{7}{|c|}{ Faculdades CEFET/IFET } \\
\hline 2008 & 2.252 & 183 & 124 & $911^{*}$ & & 34 \\
\hline $1996 / 2001 \Delta \%$ & 39,1 & 14,7 & -- & $-31,8$ & 61,1 & --- \\
\hline $2001 / 2006 \Delta \%$ & & & & & & 511,8 \\
\hline $2001 / 2008 \Delta \%$ & 61,9 & 17,3 & 87,8 & 8,4 & & 0,00 \\
\hline $1996 / 2008 \Delta \%$ & 144,3 & 34,6 & --- & & 143,4 & - \\
\hline
\end{tabular}

Fonte: MEC/Inep/Deaes

Voltando à questão da diferenciação de esferas administrativas, já ilustrada com a diferenciação no interior da rede privada, a Tabela 6 descreve a distribuição de IES por organização acadêmica no período 1996-2008. Nela, procurou-se representar todos os tipos de IES que integraram ou integram o atual sistema de Educação Superior, segundo os dados dos censos do INEP. Basta um primeiro olhar para a tabela para constatar uma série de mudanças na própria matriz da organização acadêmica do sistema da Educação Superior, o que se constitui um desafio para a descrição da trajetória de algumas modalidades institucionais em um período mais longo (1996 2008).

As colocações acima sinalizam para a suposição de que a expansão pós-LDB/1996 parece ter atingido a base organizativa da Educação Superior na medida em que, sob os princípios da diversificação e da diversidade, adota distintos formatos institucionais e de cursos, que se configuram sob diferentes modalidades terminais (diplomas e certificados) e de modo de oferta. Mostram também a procedência da suposição de que a diversidade de formatos e de modalidades na organização institucional e acadêmica possa estar em consonância com as políticas regulatórias que impregnam a Educação Superior brasileira. 
À GUISA DE CONCLUSÕES: SINALIZAÇÃO DE RUMOS

O objetivo que norteia o presente trabalho é o de lançar luzes sobre a expansão da Educação Superior no Brasil pós-LDB/1996 na configuração da organização e das modalidades acadêmicas, sob a perspectiva de políticas públicas educacionais e sob os eixos de novas arquiteturas da EAD, de cursos tecnológicos, da internacionalização da Educação Superior e da diversidade e diversificação de modelos.

O contato com a temática, com seus marcos regulatórios e com dados expressivos da expansão da Educação Superior brasileira, bem como a sucessão sequencial de reflexões, permitem constatações e pressuposições que se mostram basilares para o prosseguimento de estudos, pois podem direcionar suas vertentes e caminhos.

Foram identificadas duas ordens de constatações: as gerais, que impregnam a Educação Superior brasileira, e as específicas, emanadas da questão de formatos e de modalidades. Ressalta-se, no entanto, que ambas revelam suas fortes ligações e caráter não exclusivo, cuja separação decorre da didática que facilita o aprofundamento temático, pois todas as constatações e os pressupostos são circunscritos pelo fenômeno indubitavelmente maior que os caracteriza, isto é, a Educação Superior brasileira em sua inserção local e global. Desse modo, não surpreende que a constatação própria de um nível descerre as tessituras de níveis antecedentes e consequentes circunscritos pela temática maior.

A primeira constatação que brota dos dados e da reflexão é a de que a expansão é uma tendência que se constrói historicamente na Educação Superior brasileira. Em que pesem diferentes encetamentos, as políticas expansionistas sempre marcaram, sejam elas dirigidas para a expansão das instituições caracterizadas pela interiorização dos anos de 1970, seja pela expansão da pós-graduação nos anos de 1980 sob a pressão da demanda econômica e de grupos ou ainda pela expansão do sistema como um todo no período pós-LDB/96 chegando à expansão qualificada pela abertura de espaços aos que estariam possivelmente excluídos do sistema e condições para permanência, já nos anos 2000.

Outra das constatações gerais é a de que a LDB/1996, marco na trajetória de expansão da Educação Superior brasileira, dentre outras medidas, flexibilizou as formas organizacionais de oferta de Educação Superior, privilegiando a diversidade e diversificação de formatos institucionais e modalidades acadêmicas, que apresentaram um crescimento percentual acentuado. A partir da promulgação da LDB/96, o contexto de mundialização, ou internacionalização, 
marcou fortemente o campo acadêmico e sua arquitetura constitutiva e, com ele, não surpreende a promulgação de políticas regulatórias adentrando a tendência macrossocietária da diversidade, da diversificação, da flexibilização e da privatização que se mostram no presente trabalho.

O contexto de expansão do ensino superior brasileiro é uma resposta às pressões educacionais e sociais. A partir dessa constatação, constrói-se o suposto de que as modalidades e formatos não surgem assepticamente, mas se vinculam a interesse de grupos. Assim ocorreu pela pressão de novos interlocutores e de classes emergentes, nos anos de 1990, e assim se dá pelos indicadores de crescimento e expansão que ressaltam a urgência de medidas equitativas, considerando, até mesmo, os esgotamentos de capacidade de sustentação econômico-financeira e as gritantes exclusões do sistema que precisavam ser superadas.

$\mathrm{Na}$ alçada, ainda, das constatações gerais, a seguinte é a de que o ensino privado, enquanto categoria administrativa da Educação Superior brasileira unívoca até 1996, passa, a partir de então, por um conjunto de reformulações que o diversificam institucionalmente. O suposto que emerge da constatação é o de que a expansão na diversificação e diversidade institucional decorrente sinaliza para distintas possibilidades de inserção.

No que se refere às constatações específicas, elas estão diretamente ligadas à organização e às modalidades de arquiteturas acadêmicas na expansão da Educação Superior e envolvem primordialmente os seguintes eixos na ampliação de espaços da Educação Superior: as políticas públicas de EAD, de educação tecnológica, as políticas públicas de formação do professor, a internacionalização da Educação Superior e a diversificação e diversidade de modelos acadêmicos.

No que diz respeito às políticas públicas de EAD e de EducaçãoTecnológica e Expansão, a constatação é a de que elas favoreceram consideravelmente a expansão da Educação Superior brasileira por meio da criação, ampliação e transformação de centros federais de educação tecnológica (CEFET), de cursos tecnológicos de graduação e de cursos de educação à distância. A suposição é a de que não necessariamente todos os formatos e modalidades de oferta de cursos abrangidos por essas categorias atendam quesitos de qualidade equitativa na Educação Superior.

No entorno da internacionalização da Educação Superior e de seu vínculo com a expansão, a constatação que se destaca é a de que a internacionalização é uma tendência do novo milênio e suas ressignificações têm presença na expansão da Educação Superior Brasileira. A suposição é a de que o modelo de transnacionalização da Educação Superior, que vem assumindo lugar como 
uma das manifestações mais pujantes da internacionalização, traz consigo aspectos culturais nem sempre compatíveis com as aspirações de qualidade equitativa esperada. Especialmente a partir da promulgação da LDB/1996, o contexto de mundialização e de internacionalização marcaram o campo acadêmico e sua arquitetura constitutiva por meio da promulgação de políticas regulatórias em consonância com a tendência macro-societária da diversidade, da diversificação, da flexibilização e da privatização.

A constatação subsequente é a de que a diversidade e a diversificação de formatos e modos organizacionais que impregnam a Educação Superior brasileira na primeira década do século XXI aumentaram consideravelmente as possibilidades de acesso dos jovens que concluem o ensino médio. Essa constatação alimenta o suposto de que a diversidade e a diversificação no ensino superior não necessariamente atendem a faixa etária populacional que deveria ingressar e permanecer na Educação Superior. A diversidade, estreitamente vinculada às políticas de inclusão social, converge para o acesso e a permanência pela via da inclusão e de ações afirmativas. Tais políticas expansionistas estão mudando estruturalmente os formatos e modos organizativos acadêmicos, pois extravasam os limites de organizações institucionais e de sua diversificação e se expandem nos currículos, segmentos, níveis e áreas da Educação Superior. A mesma constatação embasa o suposto de que a mera ampliação de tipos de organização institucional acadêmica e de tipos de instituições de educação superior mantidos ou criados pelos documentos normativos e ordenativos brasileiros pós-LDB/96, (universidades, centros universitários, faculdades isoladas, institutos superiores de educação, faculdades tecnológicas universidades tecnológicas) não são suficientes para atender ao critério da equidade de acesso e permanência, tendo como referência a população em idade escolar que deveria estar apta para ingressar, mas não está, O mesmo ocorre em relação às modalidades acadêmicas de oferta da Educação Superior quanto à presencialidade e às novas possibilidades de oferecimento de perfis formativos (cursos sequenciais, cursos tecnológicos). A equidade no acesso e a permanência na Educação Superior necessariamente passam pela expansão do Ensino Médio de qualidade, fonte real que alimenta o ensino superior. A questão da expansão também é freada pelos níveis educacionais anteriores ao superior. As crianças de sete a quatorze anos estavam todas na escola, em 2009: $98,1 \%$ frequentavam instituições educacionais. O índice de analfabetismo era de 1,9\% entre quinze e 24 anos. Mas no nível médio a situação é diferente. Não há obrigatoriedade por lei de enviar o filho à escola nem obrigatoriedade do Estado em oferecer vagas gratuitas. Nesse contexto, o Ensino Médio não é universalizado. Em 2009, entre os jovens entre quinze e dezessete anos, 
$14,8 \%$ estavam fora da escola. Em 2008, eram 15,9\%. Podemos citar também que menos da metade dos jovens no mercado de trabalho têm Ensino Médio: $40,7 \%$ dos jovens de 18-24 anos que trabalhavam ou procuravam emprego tinham, em 2009, 11 anos de estudo e 15,2 \% tinham ido além desse nível de estudo (IBGE, 2010). Assim, seriam procedentes estudos que aprofundassem a questão de impactos da expansão pela via da diversidade e da diversificação no sistema de Educação Superior, as políticas de inclusão social e especialmente a qualidade e expansão do Ensino Médio, que a alimenta.

As considerações tecidas sobre as possibilidades das diferentes mas interligadas categorias analíticas são indicativas das tensões existentes, mas também apontam para as possibilidades oferecidas pela compreensão das políticas públicas de expansão e sua configuração concreta nas suas inserções relacionais com a diversificação, a diversidade e a flexibilização na organização e modalidades acadêmicas na Educação Superior brasileira e suas tendências.

EXPANSION OF HIGHER EDUCATION IN POST-LDB/96 BRAZIL: INSTITUTIONAL AND ACADEMIC ORGANIZATION

АвSTRACT: The expansion of higher education is a global phenomenon and very few countries have reached levels of providing higher education for all. As a rule, developed countries have reached the level of providing education for all while emerging and developing countries are still at the level of providing elitist education. This article, produced as a result of the Universitas Network, analyzes the expansion of higher education in Brazil, focusing on institutional and academic organization in particular. It analyzes the post-LDB/1996 period which saw a considerable increase in the number of institutions, courses, students and teachers. The study is of a qualitative and quantitative nature (census data). Results point to an increasing complexity of the system as it adopts distinct formats of institutional and academic organization, in line with regulatory policies, including internationalization trends, diversity, diversification, liberalization and privatization.

KEYWORDS: Higher Education. Higher Education Expansion. Institutional Organization. Academic Organization. Universitas Network.

\section{REFERÊNCIAS}

ALTBACH, P. Globalization and the university: myths and realities in na unequal world. Tertiary Education And Management, Kluwer academic Publishers, 10, 2004, p. 3-25.

BRASIL. PRESIDÊNCIA DA REPÚBLICA. Decreto n. 5.622, de 19 de dezembro de 2005. Regulamenta o art. 80 da Lei n. 9.394, de 20 de dezembro de 1996, que estabelece as diretrizes e bases da educação nacional. Publicado no D.O.U. em 20/12/2005. 
Disponível em: http://portal.mec.gov.br/ sesu/arquivos /pdf/ portarias / dec5.622. pdf. Acesso em: 14 jul. 2008.

. Decreto 5224, de 01 de outubro de 2004. Dispõe sobre a organização dos Centros Federais de Educação Tecnológica e dá outras providências. Disponível em http://www.planalto.gov.br/ccivil_03/_ato2004-2006/2004/decreto/d5224.htm. Acessado em 19/04/2011.

FÁVERO, M. L. A.; SEGENREICH, S.C.D. Universidades e Centros Universitários pósLDBEN/1996: tendências e questões. In: BITTAR, M., OLIVEIRA, J. F. MOROSINI, M. Educação Superior no Brasil - 10 anos pós - LDB. Brasília: Instituto Nacional de Estudos e Pesquisas Educacionais Anísio Teixeira, 2008.

FRANCO, M. E. D. P. Educação Superior e modelos institucionais. In: MOROSINI, Marilia Costa (Editora). Seminário Internacional de Educação Superior na Comunidade de Países de Língua Oficial Portuguesa - CPLP (Recurso Eletrônico). Porto Alegre, EdiPUCRS, maio p.61-65, 2009. Disponível em <http://www.pucrs.br/edipucrs/publicaçõeseletrônicas/ anais/cplp>, maio Em vu-book artigo completo.

IBGE. PNAD. Pesquisa Nacional de Amostragem a Domicilio. Brasília: IBGE, 2010.

IESALC/UNESCO. <http://www.iesalc.unesco.org.ve/ pruebaobservatorio/boletin No118.htm>. Acesso: 20 abr. 2006).

LANCRIN, S. Building future scenarios for universities and higher education: an international approach. In: MARGISONS, S. (ed.) Prospects of Higher Education: globalization, market competition, public goods and the future of the university. Rotterdam: Sense Publishers, 2007, p. 03-28.

MEC. Instituições de Educação Superior a distância - cursos de Pós-graduação Lato sensu a distância Disponível em: $<$ http://portal.mec.gov.br/sesu/index.php?option= content\&task=view\&id=590> Acesso em: 18 jul. 2008.

MEC. Instituições de Educação Superior a distância. Disponível em: <http://portal.mec. gov.br/sesu/index.php?option=content\&task=view\&id=588>. Acesso em: 18 jul. 2008.

MOROSINI, M. C. (ed. chefe) Enciclopédia de Pedagogia Universitária. v. 2. Glossário: Brasília: INEP/RIES, 2006.

NEAVE, Guy. On the cultivation of quality, efficiency and enterprise: an overview of recents trends in higher education in Western Europe: 1986 - 1988. European Journal of Education, v. 23, n. 1/2, p. 7-23, 1988.

REUNI-2007. Disponível em: <http://portal.mec.gov.br/sesu/arquivos/pdf/> Acesso em 18 jul. 2008.

RISTOFF, D; GIOLO, J. Introdução: A Educação Superior no Brasil: panorama geral. In: (org.). Educação superior brasileira 1991- 2004. Brasilia: INEP, 2006 
SEGENREICH, S.C.D. ProUni e UAB como estratégias de EAD na expansão do Ensino Superior. Pró-Posições. Campinas: Unicamp, v.20, n. 2, v. 59, maio/ago., p. 205-22, 2009.

Desafios da Educação a Distância ao Sistema de Educação Superior: novas reflexões sobre o papel da avaliação. Educar em Revista. n. 28, jul-dez, p.161-77, 2006.

; CASTANHEIRA, A. M. Expansão, privatização e diferenciação da Educação Superior no Brasil pós-LDBEN/96: evidências e tendências. Ensaio: avaliação e políticas públicas em educação. Rio de janeiro: Fundação Cesgranrio, v.17, n. 62, jan./mar., p.55-86, 2009.

TROW, M. From mass higher education to universal Access: the American advantage. Minerva: Kluwer Academy Publishing, 1999, 301-28.

UVALIĆ-TRUMBIĆ. Stamenka. Internationalizing Quality Assurance: a New Dynamic for Higher Education in the $21^{\text {st }}$ century" International Seminar innovation and higher education in the university. September $10^{\text {th }}, 2010$, PUCRS. Disponível em <http://www. pucrs.br>. Acesso em 6.10.2010.

UAB. Resultados do $1^{\circ}$ (2005) e $2^{\circ}$ (2006) edital. Disponível em: <http://www.uab.capes. gov.br/index.php?option=com_wrapper\&view>. Acesso em: 18 jul. 2008.

VAIRA, M. Globalization and higher education organizational change: a framework for analysis. Higher Education, n.:48, p. 483-510, 2004.

MARILIA COSTA MOROSINI é professora da Faculdade de Educação da PUCRS, pesquisadora $1 \mathrm{~B}$ do CNPq e pós-doutora no LLILAS - U Texas - Austin. Coordenadora da Rede Universitas.

E-mail: marilia.morosini@pucrs.br

Maria Estela Dal Pal Franco é professora titular do PPGEdu da UFRGS, líder do grupo de pesquisa do CNPq - GEU-Ipesp/Edu/ UFRGS: Grupo de Estudos sobre Universidade Inovação e Pesquisa. Integra a rede Universitas de pesquisa, ligada ao GT de Política da Educação Superior da ANPED. É membro do Conselho da Rede Sul Brasileira de Investigadores de Educação Superior (RIES).

E-mails: medalpaifranco@urrgs.br; medpf@orion.ufrgs.br

Stella Cecilia Duarte Segenreich é professora titular do Mestrado em Educação da Universidade Católica de Petrópolis, lider do grupo de pesquisa do CNPq Educação a Distância: possibilidades e questões. Integra a rede Universitas de pesquisa e é ligada ao GT de Política da Educação Superior da ANPED.

E-mail: stella.segen@terra.com.br 